\title{
Time for a reappraisal at the Select Committee
}

THE House of Commons Select Committee on Science and Technology is always an easy target for criticism. It has little money, limited time, few administrative resources. It possesses no legislative power, and shows a frustrating inability to influence intractable government departments.

This bleak picture is made worse by the committee's history of ill-prepared reports and badly formulated proposals, themselves often the product of seemingly sloppy if not uncaring hit-and-miss investigations unbecoming of serious parliamentary procedure. (Remember how the committee championed the illfated proposal to appoint a Minister of Research and Development?)

To cap it all, the committee last week published its report on a visit recently made to the Gulf states of Abu Dhabi and Kuwait to investigate "matters of oil policy and related energy questions". The somewhat inappropriate main recommendation was that more effort should go into the export of Range Rover automobiles to Arab countries. But more disturbing was its remark (an attempt at vindication?) concerning the Britishbuilt Steam Generating Heavy Water Reactor (SGHWR): "We were puzzled by reports that the ... SGHWR cannot be submitted to overseas buyers until a commercial size reactor has been successfully constructed at home."

The committee should be familiar with the problems that have arisen with the Advance Gas Cooled Reactor because of premature scaling-up, and should know that present policy consequently demands stringent, highly detailed design specifications, still not achieved with the SGHWR. The chairman of the committee attempted to justify its thinking with the observa- tion that Britain should not worry if other states are prepared to accept safety standards less stringent that its own.

The committee's approach suggests that it has become as disillusioned with its own role as everybody else has; an attitude of cynical self-disdain does disservice to British science and technology. The need for well informed, disinterested guidance is perhaps greater now than ever before.

Nobody can be expected to take this committee more seriously than it will take itself. It is time for a reappraisal, a move towards the professionalism and rigour customarily associated with the (admittedly better off) Congressional committees on the other side of the Atlantic. It does not require bottomless coffers and endless time to stop and consider the difference between disinterested and uninterested.

\section{Seeking sense about scientists in government}

The debate over Civil Service scientists in the UK continues. Harold Turner of the National Physical Laboratory gives his view and takes up some of the issues raised in Nature's columns by Cyril Cooper last November and David Budworth in February.

Civil Service baiting has become a popular national pastime. The points raised in relation to the science aspects of the sport fall into two main categories: first, those which question the role of the Scientific Civil Service (SCS) within British science and the British economy generally; and, second, those that are concerned with the organisation, structure and competence of the SCS itself. Any evaluation of the criticisms of the SCS must first look at the broader, overwhelmingly more important issues in the former category.

The growth of the SCS arose, not from a doctrinaire belief in Government science, but from the need to provide national scientific services, such as standards and geological surveys, and, in particular, from a desire to compensate for the failure of industry to undertake and apply its own research and development. The beginnings of the decline of investment in British manufacturing industry, and its replacement by the more immediately profitable alternative of invest- ment abroad, had been perceived by some as early as the $1860 \mathrm{~s}$, and the First World War finally brought home to Government that much of British industry was so backward as to bring national survival into question.

The steps thus set in motion-to encourage research in industry, to set up Research Associations and Government research establishments-have led to the pattern we see today. In a very few areas, notably chemicals, industry itself now mounts a research and development effort comparable with that of our major competitors. In a few others, contributing only a small part of our industrial output, there is (for reasons linked with present or past defence policy) an overwhelming concentration of government support. For the rest, representing some $85 \%$ of our industrial output, there is an effort which is inadequate by any standards. This maldistribution of effort has persisted for a considerable time, through many successive governments. The failure of our large research and development expenditure (about $2.3 \%$ of GNP) to produce any comparable improvement in economic performance, can be seen to be due to an excessive concentration on high technology, to a general failure on the part of industry to undertake and apply its own research and development, and to a failure of both Government and industry to secure the application in industry of research and development carried out in the public sector and the universities.

In the late 1940s many people, including myself, believed that the technological and competitive weakness of much of British industry could be overcome through a research effort in which Government research establishments played an important part: that the successes of wartime research could be repeated in peacetime conditions. We believed that if we provided research and perhaps some of the development, industry would provide the production and marketing expertise, and investment and economic growth would follow. We thought that our contacts with industry and the involvement of industrialists in the work would ultimately ensure its relevance.

Now, sadly, nearly 30 years later, after passing through phases in which science has been alternately oversold 